\title{
Теплопроводность градиентно-неоднородных ветвей термоэлементов при рабочем перепаде температур
}

\author{
(C) В.И. Бочегов ${ }^{1}$, В.М. Грабов ${ }^{2,9}$ \\ ${ }^{1}$ Курганский государственный университет, \\ 640000 Курган, Россия \\ ${ }^{2}$ Российский государственный педагогический университет им. А.И. Герцена, \\ 191186 Санкт-Петербург, Россия \\ IE-mail: vmgrabov@yandex.ru
}

(Получена 27 декабря 2016 г. Принята к печати 12 января 2017 г.)

Экспериментально установлено существенное различие теплопроводности градиентно-неоднородных ветвей термоэлементов при рабочем перепаде температуры в случаях параллельного и антипараллельного направлений градиентов температуры и состава. Полученные результаты следует учитывать при использовании градиентно-неоднородных материалов для оптимизации термоэлектрических преобразователей энергии.

DOI: $10.21883 /$ FTP.2017.07.44640.26

\section{1. Введение}

Обычно в рабочем режиме термоэлемента перепад температур между горячим и холодным сечениями ветвей составляет десятки кельвинов. Так как большинство эффективных термоэлектрических материалов являются полупроводниками, то вследствие существенной зависимости концентрации и кинетических параметров носителей заряда от температуры ветви термоэлементов фактически являются неоднородными с некоторым распределением термоэлектрических параметров вдоль ветвей. В этом случае интегральный коэффициент теплопроводности $\langle k\rangle$ в выражении $j_{Q}=-\langle k\rangle(\Delta T / L)$, в котором $j_{Q}$ - плотность теплового потока, $L-$ длина ветви термоэлемента, $\Delta T-$ перепад температуры, может быть записан в виде

$$
\langle k\rangle=\left[\frac{1}{L} \int_{0}^{L} \frac{d x}{k(T(x))}\right]^{-1} .
$$

Под действием рабочего перепада температур исходно однородный по составу материал ветвей термоэлемента становится градиентно-неоднородным в направлении теплового потока и далеко не всегда оптимальным по параметрам во всех сечениях. Для оптимизации ветвей термоэлемента в этом случае целесообразно использовать так называемые градиентно-неоднородные, или функционально-неоднородные материалы с распределенным вдоль ветвей составом [1-3]. В этом случае вдоль ветви термоэлемента в каждом сечении с координатой $x$ локальный коэффициент теплопроводности будет зависеть от координаты через координатную зависимость состава - например, доли компонента в твердом растворе $\gamma(x)$ и температуры $T(x)$

$$
k(x)=k(\gamma(x), T(x)) .
$$

Очевидно, что при параллельности или антипараллельности градиентов состава и температуры вдоль ветвей термоэлементов функция $k(x)(2)$ будет различной, что приведет к различию значений интегрального коэффициента теплопроводности

$$
\langle k\rangle=\left[\frac{1}{L} \int_{0}^{L} \frac{d x}{k(\gamma(x), T(x))}\right]^{-1}
$$

при приложении одинакового перепада температуры к ветвям термоэлементов в этих двух случаях. Для экспериментального установления предполагаемой закономерности были выбраны кристаллы твердых растворов висмут-сурьма, теплопроводность которых характеризуется существенной зависимостью от состава и температуры в интервале температур $T=80-300 \mathrm{~K}$ [4].

\section{2. Эксперимент}

Первые экспериментальные результаты, указывающие на существенное различие интегральных коэффициентов теплопроводности (3) градиентно-неоднородных кристаллов висмут-сурьма при параллельном и антипараллельном направлениях градиентов состава и температуры, были получены одним из авторов данной работы (В.И. Бочеговым) с применением апробированного стационарного метода $[5,6]$. Для повышения надежности этого впервые полученного результата были приняты меры по модернизации методики и техники измерения коэффициента теплопроводности, минимизации погрешностей измерения до $\sim 5 \%$ [7]. Измерения интегрального коэффициента теплопроводности выполнены на образце размерами $15 \times 7 \times 1.4$ мм, вырезанном из специально выращенного методом зонной перекристаллизации кристалла висмут-сурьма с близким к линейному распределением компонентов вдоль слитка. На рисунке представлены зависимости интегрального коэффициента теплопроводности образца градиентно-неоднородного анизотропного кристалла висмут-сурьма $\langle k\rangle=k_{22,1}$ при 


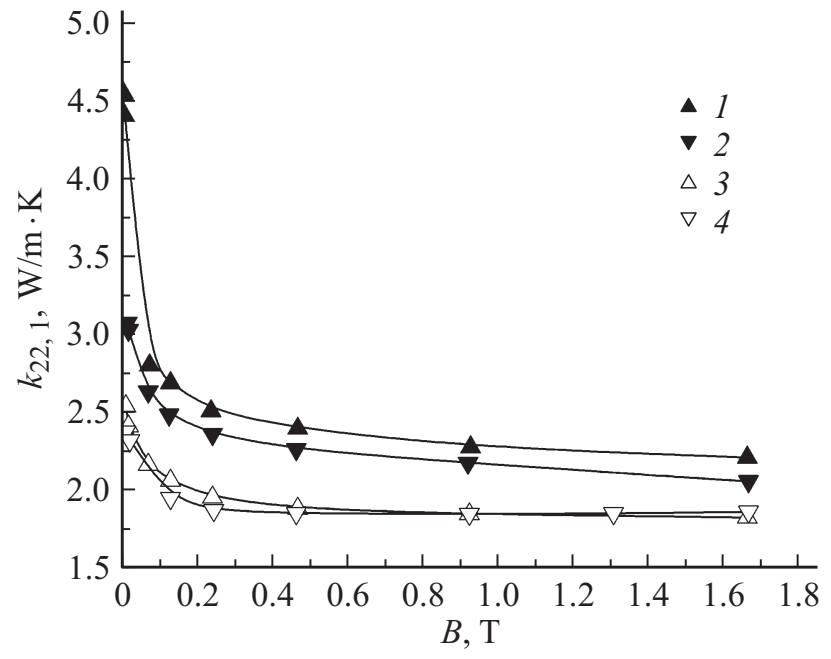

Зависимость теплопроводности от величины индукции поперечного магнитного поля в кристалле $\mathrm{Bi}_{100-C} \mathrm{Sb}_{C}$, размерами $15 \times 7 \times 1.4 \mathrm{Mм,} \mathrm{с} \mathrm{параметрами}\langle C\rangle=(7.6 \pm 0.5)$ ат\%, $\nabla C=(6.3 \pm 1.3) \mathrm{aT} \% / \mathrm{cm}$ при среднем значении температуры и ее градиента: $(1,2)-T=(94.3 \pm 1.2) \mathrm{K}$, $\nabla T=(7.4 \pm 0.5) \mathrm{K} / \mathrm{cm} ; \quad(3,4)-T=(86.5 \pm 0.3) \mathrm{K}, \quad \nabla T=$ $=(2.7 \pm 0.1) \mathrm{K} /$ см. 1,3 соответствуют направлениям градиентов $\nabla T \uparrow \downarrow \nabla C, 2,4-\nabla T \uparrow \uparrow \nabla C$. Тепловой поток направлен вдоль кристаллографической оси $\mathbf{C}_{2}$. Вектор магнитной индукции В направлен перпендикулярно тепловому потоку, параллельно кристаллографической оси $\mathbf{C}_{1}$.

направлении векторов градиента температуры и плотности теплового потока вдоль оси $\mathbf{C}_{2}$ в зависимости от величины магнитного поля, вектор индукции $\mathbf{B}$ которого направлен параллельно оси $\mathbf{C}_{1}$.

Из приведенных на рисунке результатов следует, что наблюдается существенное, примерно в 1.5 раза, различие интегральных значений коэффициента теплопроводности при параллельном и антипараллельном направлениях градиентов температуры $\nabla T=(7.4 \pm 0.5) \mathrm{K} / \mathrm{cm}$ и градиента концентрации сурьмы в кристаллах висмутсурьма $\mathrm{Bi}_{100-C} \mathrm{Sb}_{C} \quad \nabla C=(6.3 \pm 1.3) \mathrm{aT} \% / \mathrm{cm} \quad$ в отсутствие магнитного поля, так что этот результат следует считать достоверно установленным. Различие значений $\langle k\rangle$ уменьшается при уменьшении градиента температуры. Существенное уменьшение интегральной теплопроводности и ее различия в зависимости от магнитного поля указывают на существенный вклад носителей заряда в перенос теплоты и в различие интегральных коэффициентов теплопроводности при параллельном и антипараллельном направлениях градиентов состава твердого раствора висмут-сурьма и температуры.

\section{3. Заключение}

Впервые обнаруженный эффект асимметрии интегрального коэффициента теплопроводности градиентнонеоднородных материалов в рабочем интервале температур ветвей термоэлементов относительно взаимного на- правления градиентов состава и температуры открывает новые возможности управления термоэлектрическими параметрами функционально-неоднородных термоэлектрических материалов и их оптимизации.

Работа выполнена при финансовой поддержке Министерства образования и науки Российской Федерации.

\section{Список литературы}

[1] Л.И. Анатычук, Л.Н. Вихор. Термоэлектричество (Черновцы, Ин-т термоэлектричества, 2012) т. 4.

[2] О.И. Марков. ЖТФ, 75 (2), 62 (2005).

[3] О.И. Марков. ЖТФ, 75 (6), 132 (2005).

[4] В.М. Грабов, Г.А. Иванов, В.С. Понарядов. ФТТ, 12 (1), 267 (1970).

[5] Дж. Драбл, Г. Голдсмит. Теплопроводность полупроводников (М., Иностр. лит., 1963).

[6] В.М. Глазов, А.С. Охотин, Р.П. Боровикова, А.С. Пушкарский. Методы исследования термоэлектрических свойств полупроводников (М., Атомиздат, 1969).

[7] В.И. Бочегов, В.М. Грабов, А.С Парахин. Измерительная техника. Теплофизические измерения, 4, 22 (2014).

Редактор Л.В. Шаронова

\section{The thermal conductivity of gradient-inhomogeneous branches of thermoelements at operating temperature difference}

\author{
V.I. Bochegov ${ }^{1}$, V.M. Grabov ${ }^{2}$ \\ ${ }^{1}$ Kurgan State University, \\ 640000 Kurgan, Russia \\ ${ }^{2}$ Herzen State Pedagogical University, \\ 191186 St. Petersburg, Russia
}

\begin{abstract}
Significant difference in the thermal conductivity of gradient-inhomogeneous branches of thermoelements at operating temperature difference in the cases of parallel and antiparallel directions of the temperature and composition gradients is established experimentally. Results should be taken into account in using a gradient-inhomogeneous materials for thermoelectric energy converters optimization.
\end{abstract}

